\title{
Application of Statistical Design Strategies to Optimize the Preparation of CuO Nanoparticles by Hydrothermal Technique
}

\author{
Reda Mohamed $^{1,2^{*}}$, Ibreheem Mkhalid ${ }^{1}$, Elham Azaam ${ }^{1}$ \\ ${ }^{1}$ Chemistry Department, Faculty of Science, King Abdulaziz University, Jeddah, KSA; ${ }^{2}$ Central Metallurgical R\&D Institute, \\ CMRDI, Cairo, Egypt. \\ Email: redama123@yahoo.com
}

Received January $23^{\text {rd }}, 2011$; revised March $10^{\text {th }}, 2011$; accepted June $7^{\text {th }}, 2011$.

\begin{abstract}
Synthesis of $\mathrm{CuO}$ nanoparticles by hydrothermal technique in presence of cetyltrimethylammonium bromide (CTAB) as surfactant was carried out by statistically designed experiments based on Box Behnken method. Reaction parameters as time, temperature and surfactant concentration have been studied to show their effect on $\mathrm{CuO}$ particle size and morphology. The results of experimental design indicate that the surfactant concentration, reaction time and temperature were significant in $\mathrm{CuO}$ particles were characterized using XRD and SEM. These work findings showed that $\mathrm{CuO} \mathrm{na-}$ noparticles were formed at $100^{\circ} \mathrm{C}$. On other hand, their crystallinity was improved with rising temperature from 100 to $200{ }^{\circ} \mathrm{C}$ to achieve particle size of $\mathrm{CuO}$ in the range of $49-92 \mathrm{~nm}$.
\end{abstract}

Keywords: Statistical Design, CuO, Nanoparticles, Surfactant, Hydrothermal

\section{Introduction}

Nanocrystalline semiconductor particles have drawn considerable interest in recent years because of their special properties such as a large surface to-volume ratio, increased activity, special electronic properties and unique optical properties as compared to those of the bulk materials $[1,2]$. The oxides of transition metals are an important class of semiconductors, which have applications in magnetic storage media, solar energy transformation, electronics and catalysis [3-12]. Among the oxides of transition metals, $\mathrm{CuO}$ has attracted much attention because it is the basis of several high-Tc superconductors. $\mathrm{CuO}$ is a semiconducting compound with a narrow band gap and used for photoconductive and photothermal applications [13]. However, up to now, the reports on the preparation and characterization of nanocrystalline $\mathrm{CuO}$ are relatively few contrariwise to other transition metal oxides such as zinc oxide, titanium dioxide, tin dioxide and iron oxide. Recently methods for the preparation of nanocrystalline $\mathrm{CuO}$ have been reported as the sonochemical method [14], sol-gel technique [15], one-step solid state reaction method at room temperature [16], electrochemical method [17], thermal decomposition of precursors [18], and co-implantation of metal and oxygen ions [19], hydrothermal [20-22]. The optimum conditions and the interaction between the parameters for preparation of $\mathrm{CuO}$ nanosized particles are not determined yet; in this work statistically designed experiments (Box Behnken method) have been performed to study the synthesis of nanoparticles $\mathrm{CuO}$ via a low-temperature hydrothermal technique with and without surfactant as a function of the surfactant concentration, reaction time, and temperature.

\section{Experimental}

$\mathrm{CuO}$ nanoparticles were synthesized as follow: equal volume of $\mathrm{Cu}\left(\mathrm{NO}_{3}\right)_{2} \cdot 3 \mathrm{H}_{2} \mathrm{O}$ and urea $\mathrm{NaOH}$ are mixed in presence of a cetyltrimethylammonium bromide $(0-5 \mathrm{~m}$ mol) at room temperature with magnetic stirring. $\mathrm{Cu}(\mathrm{OH})_{2}$ precipitate are formed instantaneously. The $\mathrm{Cu}(\mathrm{OH})_{2}$ precipitate was separated by decantation and washed by water several times. Suspension of $\mathrm{Cu}(\mathrm{OH})_{2}$ hydrothermally treated in a teflon-lined autoclave at 100, 150 and $200^{\circ} \mathrm{C}$ for different period from 1-5 hours. After hydrothermal treatment, the samples were centrifuged and dried at $110^{\circ} \mathrm{C}$ for 24 hours. Observation of surface morphology was performed using a scanning electron microscope (SEM JEOL model JSM5410). X-ray powder 
diffraction (XRD) patterns were conducted at room temperature (RT) using Bruker axs, D8 advance using $\mathrm{Cu} \mathrm{K} \alpha$ radiation at a wavelength $0.154 \mathrm{~nm}$. Box Benhken experimental design for the variables is shown Table 1. Plots of the response surface, contours, and the best predictive models for estimating the variable response were developed. The Box-Behnken design in Table 1 can fit the following model [23];

$$
E(y)=\beta_{0}+\sum_{i=1}^{3} \beta_{i} x_{i}+\sum_{i=1}^{3} \sum_{j=1}^{3} \beta_{i j} x_{i} x_{j}
$$

where $\mathrm{y}$ is the estimate of the response variable and Xi's are the independent variables [surfactant concentration, time and temperature] that are known for each experimental run. The parameters $\beta_{0}, \beta_{i}$, and $\beta_{i j}$ are the regression parameters.

\section{Results and Discussions}

In the precipitation and hydrothermal process, the $\mathrm{CuO}$ powders form by two reactions according to the following equations:

$$
\begin{gathered}
\mathrm{Cu}\left(\mathrm{NO}_{3}\right)_{2}+2 \mathrm{NaOH} \rightarrow \mathrm{Cu}(\mathrm{OH})_{2}+2 \mathrm{NaNO}_{3} \\
\mathrm{Cu}(\mathrm{OH})_{2} \text { Hydrothermal } \mathrm{CuO}+\mathrm{H}_{2} \mathrm{O}
\end{gathered}
$$

Copper nitrate reacts with sodium hydroxide to form copper hydroxide that needs to be converted into the desired $\mathrm{CuO}$ product by hydrothermal method. X-ray diffraction and SEM results confirm the crystallinity of $\mathrm{CuO}$ with a small primary crystal size below $70 \mathrm{~nm}$, respectively. There are three variables for preparation of $\mathrm{CuO}$ nanoparticles via hydrothermal process: surfactant concentration, temperature and time. The optimum conditions using experimental design have been revealed.

\subsection{Effect of Synthetic Variables on CuO Particles Size}

Figure 1 shows that the effect of reaction time and temperature on $\mathrm{CuO}$ particle size $(0,2.5$ and $5 \mathrm{mmol}$ surfactant). The particles size was increased from 50 to $84 \mathrm{~nm}$ with increasing hydrothermal time from 1 to 5 hours in absence of surfactant as shown in Figure 1(a). Moreover, we noticed that with increasing temperature from 100 $200^{\circ} \mathrm{C}$ the particles size increased from 64 to $84 \mathrm{~nm}$ after 3 hours. The lowest particle size, $49 \mathrm{~nm}$, was achieved at low surfactant concentrations and temperature $125^{\circ} \mathrm{C}$. At 3 mmol surfactant concentration, the particles size growth was dependent on reaction time, (Figure 1(b)). Moreover, the particles size increment can be performed with rising the reaction temperature. The contour shown in Figure 1(c), at $5 \mathrm{mmol}$ surfactant concentration, illustrates that the particles size can be controlled through tuning reaction time and temperature. The surfactant addition showed pronounceable influence on growth of $\mathrm{CuO}$ nanoparticle that can be followed by observing the particles size of sample prepared in absence and presence of surfactant. However the lowest particle size can be achieved at $150^{\circ} \mathrm{C}$ for 1 hour without surfactant. Interaction graph for the particles size of $\mathrm{CuO}$ as a function of temperature and time at $2.5 \mathrm{mmol}$ surfactant concentration is shown in Figure 1(d). It reveals that the particles size of sample prepared at $100^{\circ} \mathrm{C}$ is much larger than $200^{\circ}$. This unexpected behavior might be due to removal part of CTAB attached the $\mathrm{Cu}(\mathrm{OH})_{2}$ surface during washing step the before the hydrothermal treatment. Surfactant concentration, temperature and time have a significant role for reducing $\mathrm{CuO}$ particle size.

\begin{tabular}{|c|c|c|c|c|}
\hline \multirow{2}{*}{ Run No. } & \multicolumn{3}{|c|}{ Coded Factor Levels } & \multirow{2}{*}{ Particle size, $\mathrm{nm}$} \\
\hline & Time, hr & Temperature, ${ }^{\circ} \mathrm{C}$ & Surfactant concentration, mmol & \\
\hline R1 & 1.00 & 100.00 & 2.50 & 88 \\
\hline $\mathrm{R} 2$ & 5.00 & 100.00 & 2.50 & 75 \\
\hline R3 & 3.00 & 150.00 & 2.50 & 70 \\
\hline R4 & 5.00 & 200.00 & 2.50 & 95 \\
\hline R5 & 1.00 & 100.00 & 2.50 & 88 \\
\hline R6 & 3.00 & 100.00 & 0.00 & 50 \\
\hline R7 & 3.00 & 150.00 & 2.50 & 70 \\
\hline $\mathrm{R} 8$ & 3.00 & 100.00 & 5.00 & 82 \\
\hline R9 & 1.00 & 200.00 & 2.50 & 85 \\
\hline $\mathrm{R} 10$ & 3.00 & 150.00 & 2.50 & 69 \\
\hline $\mathrm{R} 11$ & 3.00 & 200.00 & 5.00 & 105 \\
\hline $\mathrm{R} 12$ & 5.00 & 150.00 & 5.00 & 85 \\
\hline $\mathrm{R} 13$ & 3.00 & 150.00 & 2.50 & 71 \\
\hline R14 & 3.00 & 150.00 & 2.50 & 70 \\
\hline $\mathrm{R} 15$ & 3.00 & 200.00 & 0.00 & 77 \\
\hline R16 & 1.00 & 150.00 & 0.00 & 55 \\
\hline $\mathrm{R} 17$ & 5.00 & 150.00 & 0.00 & 78 \\
\hline
\end{tabular}

All the experimental data was collected at the 3-D cu-

Table 1. Experimental Box Behnken Design with the 3 levels and 3 variables utilized in the experiment. 


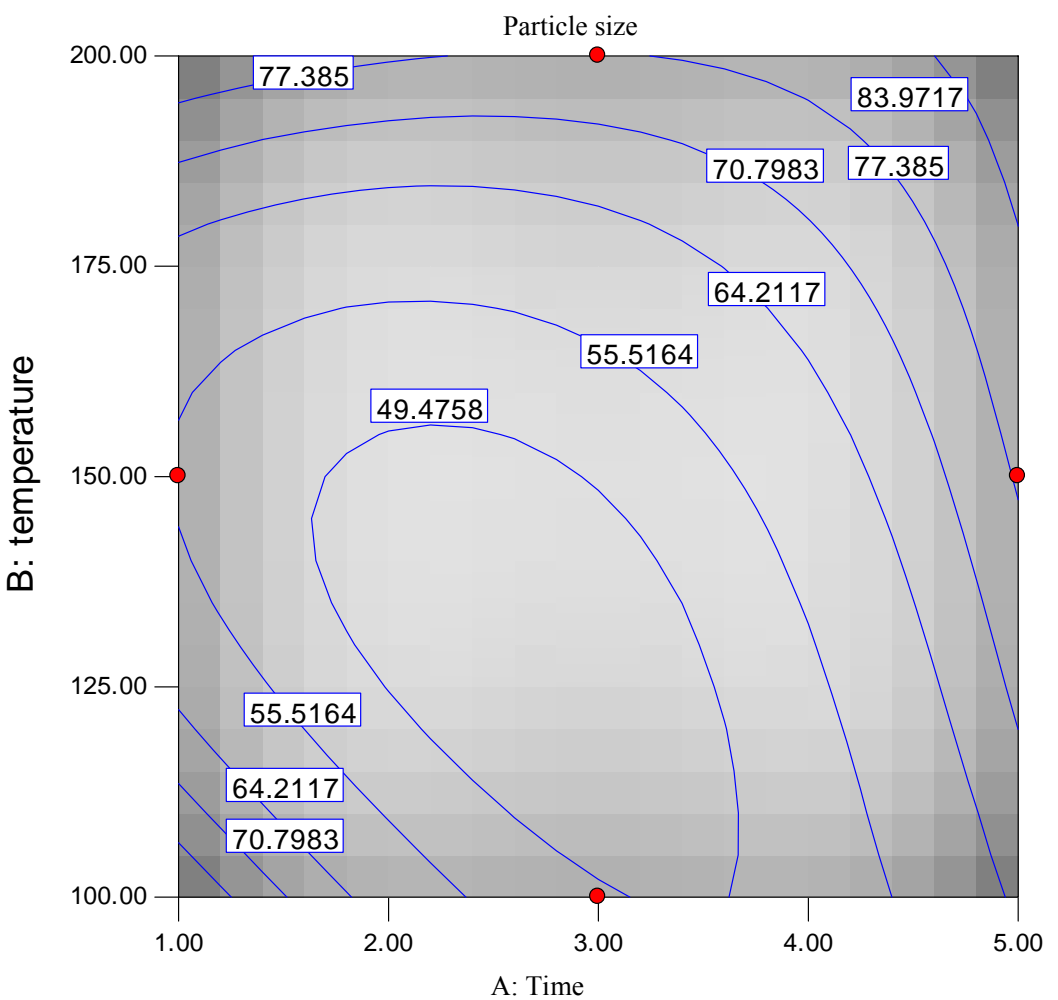

(a)

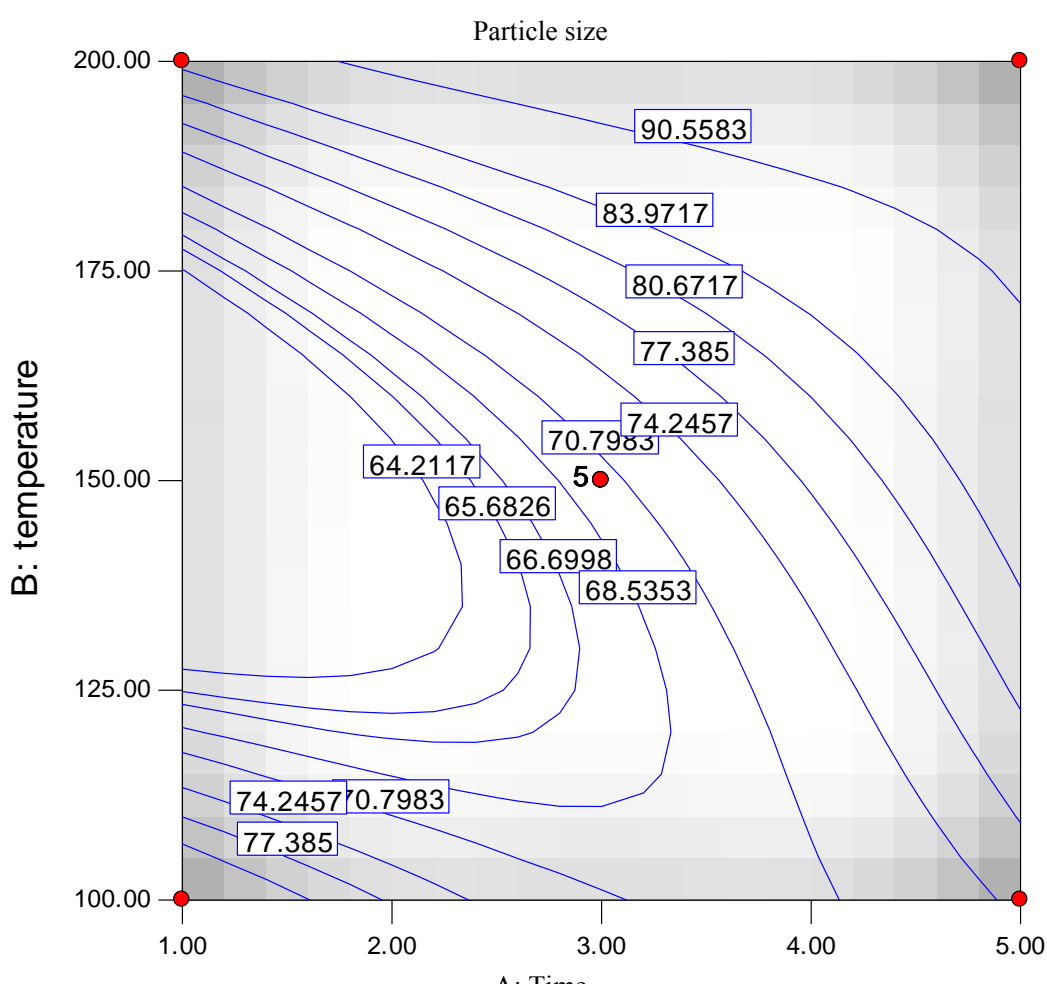

(b) 


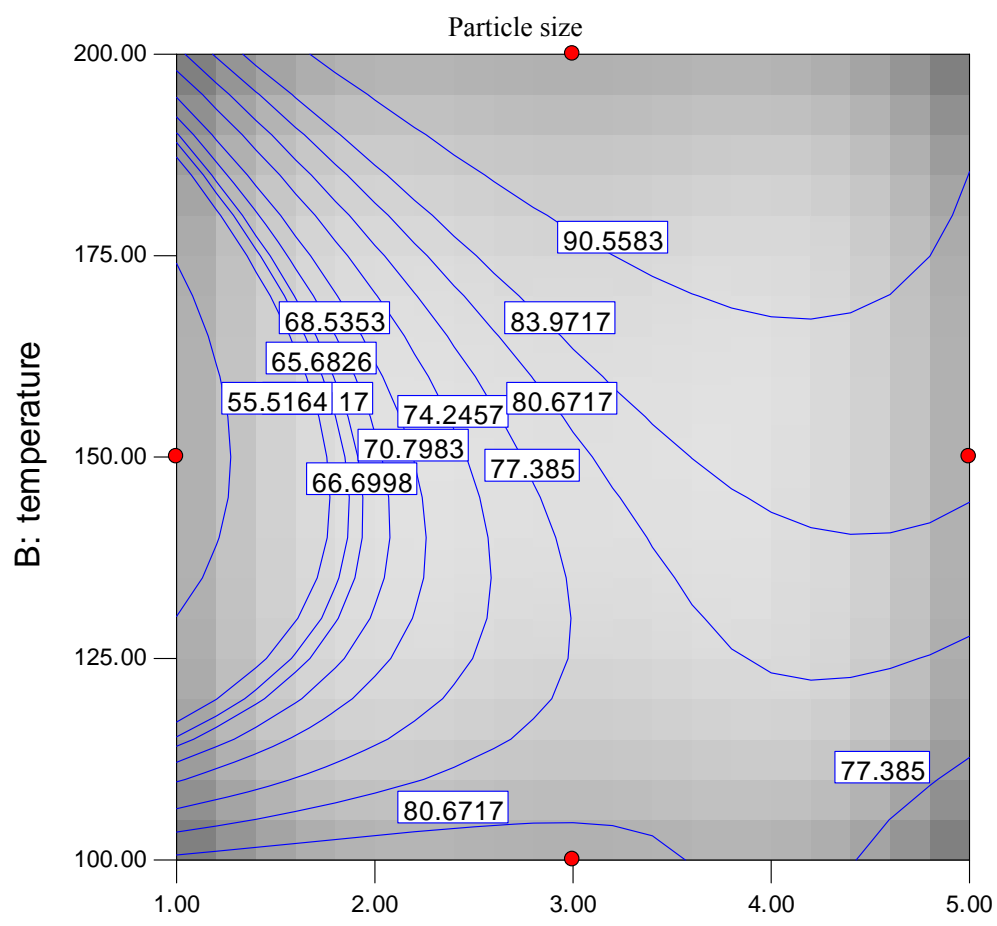

A: Time

(c)

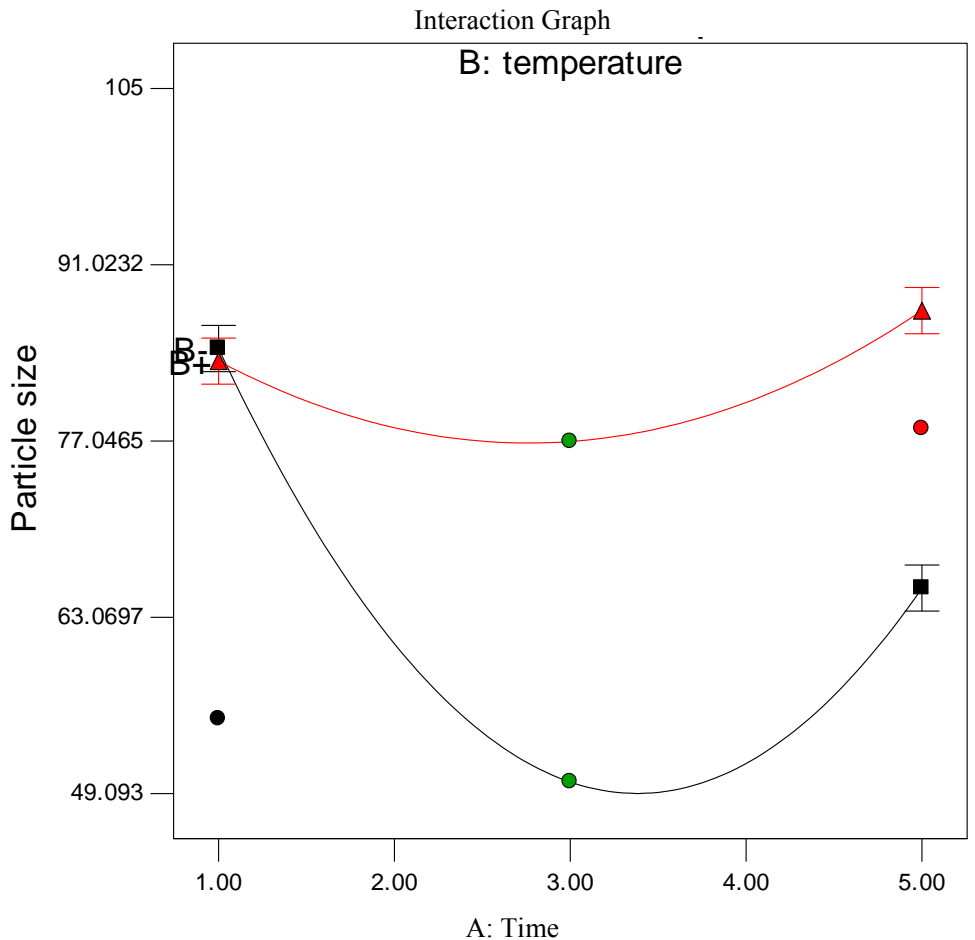

(d)

Figure 1. (a) Contour plots for the effects of time and temperature on $\mathrm{CuO}$ particles size at surfactant conc. = Zero; (b) Contour plots for the effects of time and temperature on $\mathrm{CuO}$ particles size at surfactant concentration $2.5 \mathrm{mmol}$; (c) Contour plots for the effects of time and temperature on $\mathrm{CuO}$ particles size at surfactant concentration 5 mmol; (d) Interaction graph for the effect of time and temperature at zero surfactant concentration. 
bic as shown in Figure 4. The data revealed that particles size was ranged from 65 to $92 \mathrm{~nm}$. At low temperature, $100^{\circ} \mathrm{C}$, and long reaction time without surfactant, the particle size was $65 \mathrm{~nm}$. Rising temperature to $200^{\circ} \mathrm{C}$ the particles size increased to $83 \mathrm{~nm}$. On the other hand, at low temperature and short reaction time without surfactant the particle size was $88 \mathrm{~nm}$. With rising temperature to $200^{\circ} \mathrm{C}$ and surfactant concentration to $5 \mathrm{mmol}$, the particles size was increased to $92 \mathrm{~nm}$. Under such conditions, low surfactant concentration would be desirable for less aggregation.

The diagnostic results provide plot that can be used to analyze the data, which is plot of predicted values as a function of experimentally observed values for the particle size of $\mathrm{CuO}$ when the surfactant concentration, time and temperature are changed. These plot show that there is a linear relationship between the experimentally observed and predicted values from the model, and also that the differences between observed and predicted values are in the range of $\pm 1 \%$. These indicate that experiments were conducted well and the results are not carrying any significant error. Also the standard deviation was 0.71 and $\mathrm{R}^{2} 0.9994$.

\subsection{XRD Patterns}

The XRD patterns of five $\mathrm{CuO}$ powders were determined and similar results were obtained. Here, R2, R3, R11 and

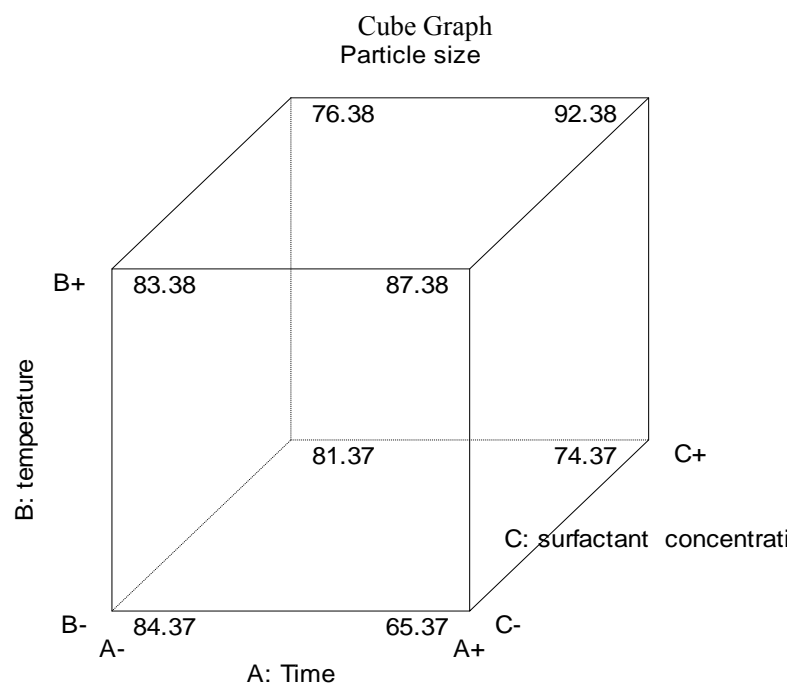

Figure 2. 3-D plot for all experimental data.

R15 were selected as an example to reveal the effect of temperature and surfactant concentration on the XRD patterns as shown in Fiure 3. There are no noticeable changes in the crystallographic patterns and intensity ratios among peaks. But, a clear sharpening and attenuation of peaks can be observed with increasing the temperature. Pure $\mathrm{CuO}$ powder is formed only after hydro-

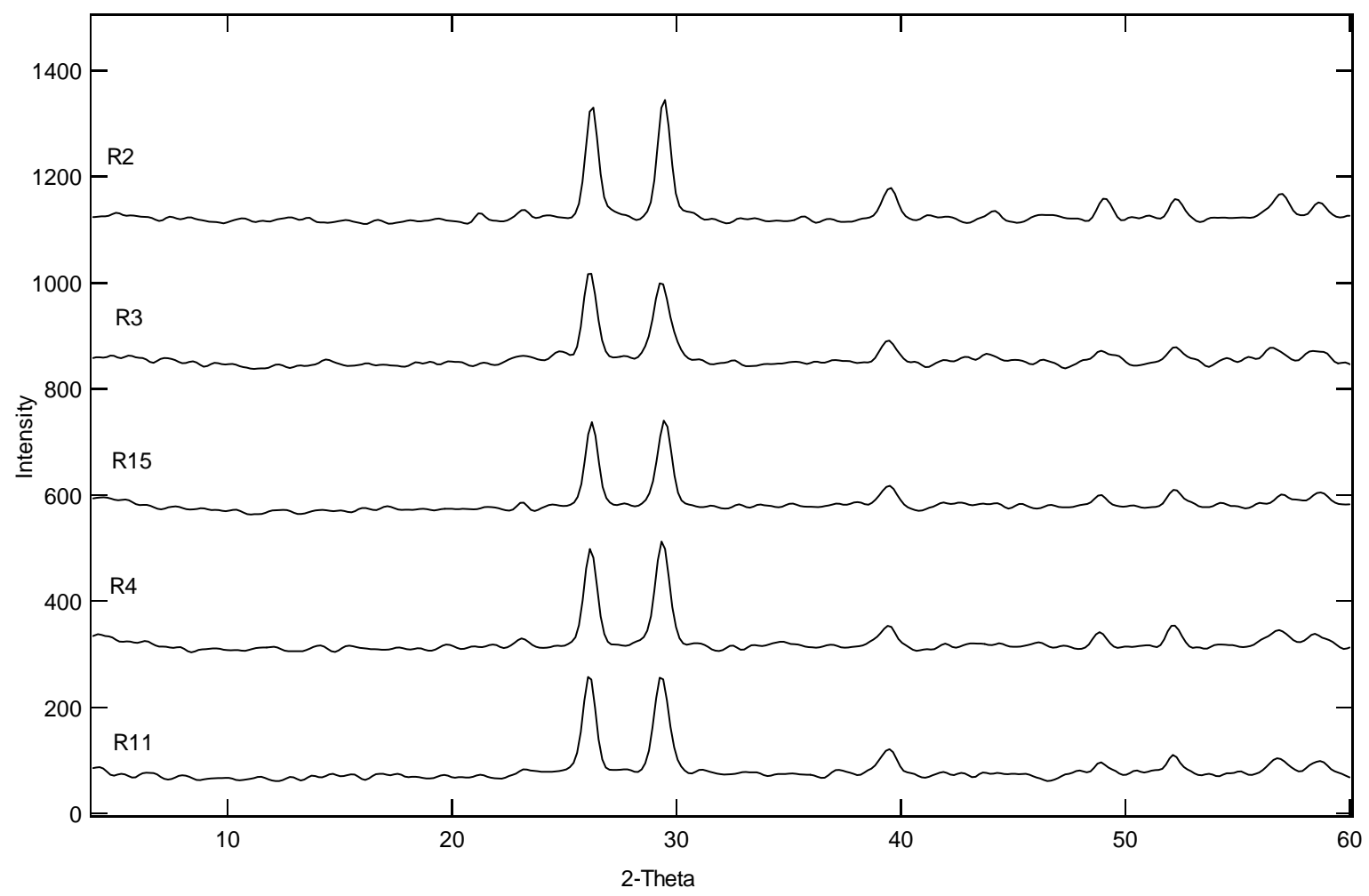

Figure 3. XRD patterns of CuO nanoparticles for R2, R3, R11 and R15 samples. 


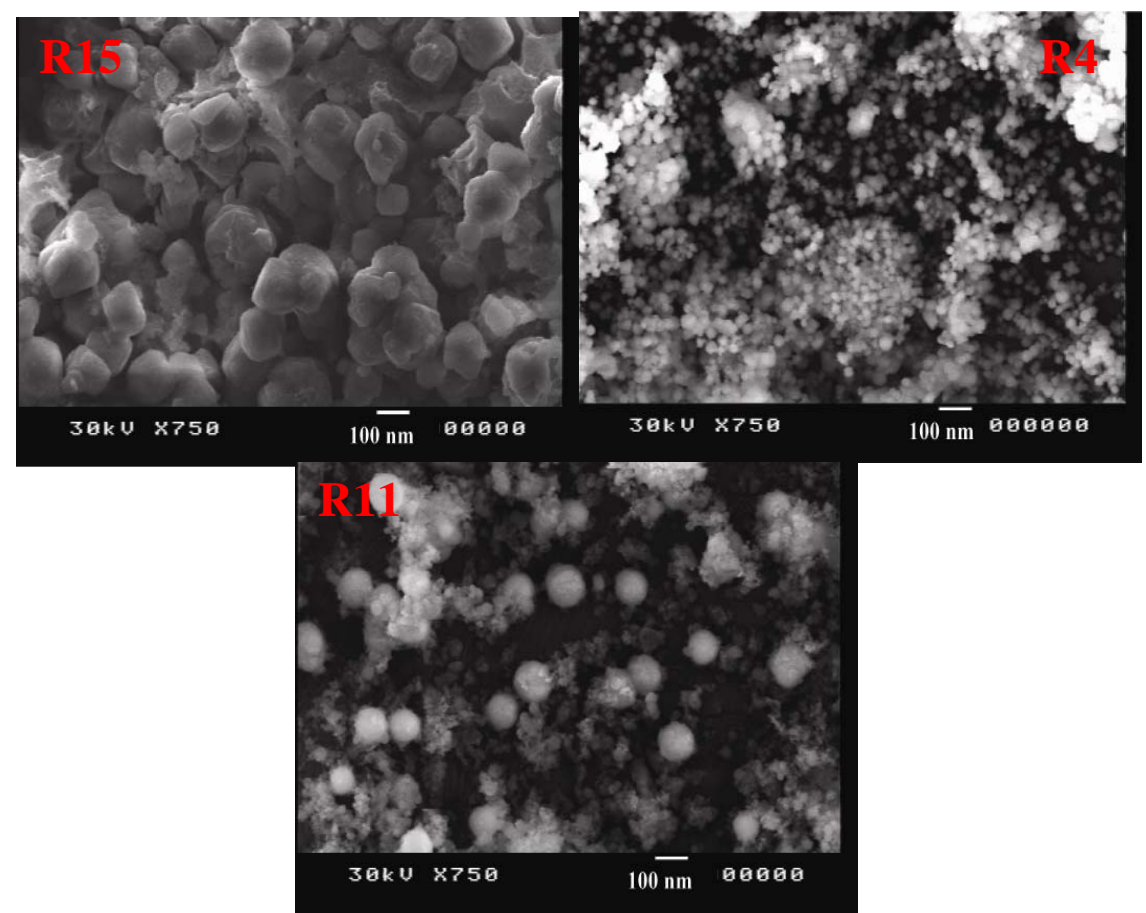

Figure 4. SEM surface morphology of R4, R11 and R15.

thermal heating at $100^{\circ} \mathrm{C}$. In general, the peak sharpening in XRD patterns can be ascribed to the increasing of crystallite size. On other word, the increase in the intensity of diffraction peaks is attributed to the increase in the crystallinity of the obtained powder [24-25].

\subsection{SEM Morphology}

The SEM micrographs of $\mathrm{CuO}$ powder prepared at different conditions are presented in Figure 4. R4, R11 and $\mathrm{R} 15$ are selected to be representative samples for all different conditions. At R15 without surfactant, particle shape of $\mathrm{CuO}$ powder is cubic. R4 and R11 with surfactant concentration of 2.5 and $5 \mathrm{mmol}$, the particle morphology are become spherical after surfactant addition. This means that, CTAB as surfactant is playing an important role for modifying the particles morphology.

\section{Conclusions}

Statistically designed experiments based on Box Behnken method were achieved to synthesize $\mathrm{CuO}$ nanoparticle in presence CTAB as surfactant by hydrothermal technique. $\mathrm{CuO}$ is formed only after hydrothermal heating at $100^{\circ} \mathrm{C}$. Compared to other method for synthesizing copper oxide powders, the reaction conditions are considerably moderate. It was found that, the surfactant concentration, reaction time and temperature were significant in tuning the particle size. The morphology of $\mathrm{CuO}$ particles was modified, from cubic structure to spherical one, using CTAB surfactant. The particle sizes of the $\mathrm{CuO}$ produced are ranged from 49 to $92 \mathrm{~nm}$.

\section{REFERENCES}

[1] B. J. Jin, S. H. Bae, S. Y. Lee and S. Im, "Effects of Native Defects on Optical and Electrical Properties of Zno Prepared by Pulsed Laser Deposition," Material Science Engeneerig B, Vol. 71, No. 1-3, 2000, pp. 301-305. doi:10.1016/S0921-5107(99)00395-5

[2] P. Zu, Z. K. Tang, G. K. L. Wong, M. Kawasaki, A. Ohtomo, H. Koinuma and Y. Segawa, "Ultraviolet Spontaneous and Stimulated Emissions from zno Microcrystallite Thin Films at Room Temperature," Solid State Commun, Vol. 103, No. 8, 1997, pp. 459. doi:10.1016/S0038-1098(97)00216-0

[3] E. Ohshima, H. Ogino, I. Niikura, K. Maeda, M. Sato, M. Ito and T. Fukuda, "Growth of the 2-in-size Bulk ZnO single Crystals by the Hydrothermal Method," Journal Crystal Growth, Vol. 260, No. 1-2, 2004, pp. 166-170. doi:10.1016/j.jcrysgro.2003.08.019

[4] T. L. Yang, D. H. Zhang, J. Ma, H. L. Ma and Y. Chen, "Transparent Conducting ZnO: Al Films Deposited on Organic Substrates Deposited by r.f. Magnetron-Sputtering," Thin Solid Films, Vol. 326, No. 1-2, 1998, pp. 60-62. doi:10.1016/S0040-6090(98)00763-9

[5] B. Sang, A. Yamada and M. Konagai "Films for Solar Cells Grown by a Two-step Process with the Atomic Layer Deposition Technique," Japanese Journal Applied Physics, Vol. 37, 1998, pp. 206-208. doi:10.1143/JJAP.37.L206 
[6] J. F. Cordaro, Y. Shim and J. E. May, "Bulk electron traps in zinc oxide varistors," Journal Applied Physics, Vol. 60, No. 12, 1986, pp. 4186-4191. doi:10.1063/1.337504

[7] P. Verardi, N. Nastase, C. Gherasim, C. Ghica, M.Dinescu, R. Dinu and C. Flueraru, "Scanning force Microscopy and Electron Microscopy Studies of Pulsed Laser Deposited Zno Thin Films: Application to the Bulk Acoustic Waves (Baw) Devices," Journal Crystal Growth, Vol. 197, No.3, 1999, pp. 523-528. doi:10.1016/S0022-0248(98)00808-2

[8] X. Tang, E. Shi G. Choo, L. Li, J. Ding and J. M. Xue, "One-Pot Synthesis of Water-Stable ZnO Nanoparticles via a Polyol Hydrolysis Route and Their Cell Labeling Applications," Langmuir, Vol. 25, No. 9, 2009, pp. 52715275. doi:10.1021/la900374b

[9] I. Irzh, L. Genish, L. Klein, A. Solovyov and A. Gedanken, "Synthesis of $\mathrm{ZnO}$ and $\mathrm{Zn}$ Nanoparticles in Microwave Plasma and Their Deposition on Glass Slides," Langmuir, Vol. 26, No. 8, 2010, pp. 5976-5984. doi:10.1021/la904499s
[10] Y. L. Zhang, Y. Yang, J. H. Zhao, R. Q. Tan, P. Cui and W. J. Song, "Preparation of ZnO Nanoparticles by a Surfactant-Assisted Complex Sol-gel Method Using Zinc Nitrate," Journal of Sol-Gel Science and Technology, Vol. 51, No. 2, 2009, pp. 198-203. doi:10.1007/s10971-009-1959-5

[11] S. M. Haile, D. W. Jonhagon, G. H. Wiserm, Aqueous "Precipitation of Spherical Zinc Oxide Powders for Varistor Applications," Journal American Ceram Socience, Vol. 72, No. 10, 1989, pp. 2004-2008. doi:10.1111/j.1151-2916.1989.tb06020.x

[12] C. H. Lu and C. H. Yeh, "Influence of Hydrothermal Conditions on the Morphology and Particle Size of Zinc Oxide Powder," Ceramics International, Vol. 26, No. 4, 2000, pp. 351-357. doi:10.1016/S0272-8842(99)00063-2

[13] J. A. Cornell and D. C. Montgomery, "Interaction Models as Alternatives to Low-Order Polynomials," Journal of Quality Technology, Vol. 28, No. 2, 1996, p. 163. 